\title{
Among friends? An examination of friendship and the self-serving bias
}

\author{
W. Keith Campbell* \\ Case Western Reserve University, USA
}

Constantine Sedikides

University of Southampton, UK

Glenn D. Reeder

Illinois State University, USA

Andrew J. Elliot

University of Rochester, USA

\begin{abstract}
Do friends bound each other's self-enhancement tendencies? Do friends display the self-serving bias (SSB; i.e. taking individual credit for success but blaming a partner for failure)? Dyads consisting of either friends or strangers engaged in an interdependent-outcomes creativity test, received bogus success or failure feedback at the dyadic level, and made responsibility attributions for the joint test performance. Strangers displayed the SSB. Friends, in contrast, refrained from the SSB: they shared responsibility for both successful and unsuccessful test outcomes. Friendship does place boundaries on self-enhancement.
\end{abstract}

Friendship improves happiness and abates misery, by the doubling of our joy and the dividing of our grief.

Few men have the strength to honour a friend's success.

Cicero $(106-43 \mathrm{BC})$

Aeschylus (525-456 BC)

Individuals manifest pervasive and persistent motivational strivings for selfenhancement (i.e. engagement in thinking or behaving that is likely to put the self under favourable light) or self-protection (i.e. avoidance of thinking or behaving that is likely to place the self under unfavourable light). ${ }^{1}$ Such strivings have been well documented (Brown \& Dutton, 1995; Sedikides, 1993; Sedikides \& Strube, 1997).

* Requests for reprints should be addressed to Dr W. Keith Campbell, Department of Psychology, Case Western Reserve University, 11220 Bellflower Road, Cleveland, OH 44106, USA (e-mail: wkc@ po.cwru.edu).

${ }^{1}$ Although the authors acknowledge the distinct motivational origins of self-enhancement vs. self-protection (e.g. Rhodewalt, Morf, Hazlett, \& Fairchild, 1991; Tice, 1991), the term 'self-enhancement' is used to mean both enhancement and protection. 
More often than not, self-enhancement strivings have been examined in isolation. Much of past research has tested whether individuals self-enhance either in the absolute (i.e. 'Am I good?') or comparatively to hypothetical others (i.e. 'Am I better than the average person?'). On many occasions, however, individuals gauge their perceived merit relative to the perceived merit of concrete others. Do individuals self-enhance in a social and, more specifically, relational context? What is, if any, the moderating influence of relational context on self-enhancement? These are the general issues with which the present research is concerned.

Relational context is defined here in terms of persons with whom the individual has a close relationship (i.e. friendship). Will individuals self-enhance or will they refrain from self-enhancement when in a friendship relationship? As the quote from Cicero implies, friendship will nurture self-enhancement. However, as Aeschylus suggests, friendship will inhibit self-enhancement. These contrasting views are tested in this research.

\section{Does friendship augment or curtail individual self-enhancement?}

Two theoretical hypotheses were developed to account for the influence of friendship on individual self-enhancement: the relationship-as-enabler hypothesis and the relationship-as-bound hypothesis (Sedikides, Campbell, Reeder, \& Elliot, 1998). The former speaks to the facilitative influence of friendship, whereas the latter addresses the inhibiting influence of friendship on self-enhancement.

The relationship-as-enabler hypothesis is supported by several lines of inquiry. Friends provide feedback that is decisively self-enhancing. Friends do not disclose their true opinion of each other (Felson, 1993), avoid judging each other (Goff man, 1959), discuss each other's positive rather than negative traits (Blumberg, 1972), distort the communicative message to make it more consistent with each other's positive self-concept (Manis, Cornell, \& Moore, 1974), and are eager to report good but not bad news (Tesser \& Rosen, 1975). Even when undesirable events do occur, friends provide each other with social support, which decreases negative affect (Cohen \& Wills, 1985), enhances well-being (Cohen \& Hoberman, 1983), and maintains self-esteem (Major, Testa, \& Bylsma, 1991). Friendships can lead to selfenhancement via additional mechanisms. Individuals will feel more positively about the self when they receive glowing feedback from friends (Jones, 1973) or when they identify with a friend's success in a non-self-relevant domain (Tesser, 1988). The self may also be enhanced when a friend is outperformed in a self-relevant domain. Indeed, the eff ect on self-esteem may be greater if one outperforms a friend than if one outperforms a stranger (Tesser, 1988). Clearly, individuals can use friendship as a springboard for own self-enhancement.

Friendships, however, may not always be congenial contexts for the enhancement of the self. Evidence for the relationship-as-bound hypothesis can be gleaned from several sources. In line with balance theory (Heider, 1958), attitudes about the self are likely to extend to friends. In fact, friends are likely to be included in an individual's self-concept (Smith \& Henry, 1996), as self-expansion theory (Aron \& Aron, 1997) has proposed. Indeed, James (1890) suggested that related others are a part of the social self, and the actions of these others are thus reflected on the self. 
Another influential theory, self-categorization theory (Turner, Oakes, Haslam, \& McGarty, 1994), postulates that the self and a friend (i.e. a member of the in-group) will be perceived as a single cognitive category. Similarly, positive views of the self often extend to include positive judgments of friends and close others (Brown, 1986; Taylor \& Koivumaki, 1976). As stated by interdependence theory and the communal-exchange relationships literature, the goal in friendships is to maximize outcomes for both persons involved (Rusbult \& Arriaga, 1997), with an accompanying genuine concern for the welfare of the friend (Clark, 1984). Likewise, in line with the extended self-evaluation maintenance model (Beach \& Tesser, 1995), friends are motivated to protect both their own and each other's self-concept. Finally, as proposed by Sedikides and Strube's (1997) self-concept enhancing tactician model, an important function of friendships is to control and attenuate the individual's selfenhancing tendencies. In summary, individuals may be as motivated to enhance their own self as their friend's self. Friendship can be a context in which one's selfenhancement strivings are curtailed.

\section{Comparative testing: The self-serving bias}

The authors in this study engage in comparative testing of the two perspectives. A useful experimental paradigm for comparative testing is one commonly used to demonstrate the self-serving bias (SSB). The SSB refers to individuals' predilection to make internal attributions following successful outcomes but to make external attributions following unsuccessful outcomes (for reviews of the SSB, see Campbell \& Sedikides, 1999; Weary-Bradley, 1978; Zuckerman, 1979). In a dyadic context, the SSB takes the form of making an internal responsibility attribution for success but blaming the other dyad member for failure. For example, a participant will take individual credit for a successful project but blame his or her partner for an unsuccessful project.

In the typical SSB experiment, two persons engage in an interdependent-outcomes task, such as a bogus test of intelligence or creativity. The dyad members work together toward a joint outcome and then receive randomly determined success or failure feedback. Feedback is at the dyadic level, as it reflects the combined contribution of the dyad members. Finally, each member allocates privately responsibility for the task outcome to the self or the partner. Importantly, the two theoretical hypotheses make conflicting predictions regarding the allocation of responsibility. The relationship-as-enabler hypothesis predicts that friendship will augment self-enhancement: that is, dyad members will display the SSB. In contrast, the relationship-as-bound hypothesis predicts that friendship will suppress selfenhancement: that is, dyad members will not display the SSB.

\section{A review of the literature}

The authors located five experiments that have examined the SSB in dyads consisting of strangers (Johnston, 1967; Sedikides et al., 1998 (two experiments); Wolosin, Sherman, \& Till, 1973 (two experiments)). Participants in each of these experiments were separated physically from their partner, but worked interdependently with the 
partner on an achievement task, i.e. a novel 'tracking task' (Johnston, 1967); a joint response-matching task (Wolosin et al., 1973); and a creativity test (Sedikides et al., 1998). Dyad members in these studies displayed the SSB: they took credit from their partners for success but blamed their partners for failure.

Only two experiments known to the present authors examined dyads consisting of close participants. Sedikides et al. (1998; Expts 1 and 2) used a version of the SSB paradigm that tested dyads in laboratory-induced (rather than naturally occurring) close relationships. In both experiments, dyad members engaged in an interdependent-outcomes creativity task. After receiving success or failure feedback, participants attributed the dyad's outcome to either the self or the partner. Dyad members refrained from manifesting the SSB. Induced closeness acted as a boundary for self-enhancement.

\section{Induced closeness vs. friendship}

No related research thus far has examined naturally occurring friendships. Will friends display the same gracious attribution style as participants in induced close relationships? That is, will friendship enable or limit self-enhancement? This question is first addressed by discussing the similarities and differences between induced close relationships and friendships.

Sedikides et al. (1998) induced relationship closeness through a structured selfdisclosure task, the Relationship Closeness Induction Task (RCIT; Sedikides, Campbell, Reeder, \& Elliot, 1999a). Strangers took turns self-disclosing for $9 \mathrm{~min}$ on a variety of progressively more personal topics.

The RCIT simulates, in part, naturally occurring friendships: following the closeness induction procedure, participants report being closer to, more similar to, and having a higher level of liking for their partners. At the same time, naturally occurring friendships differ in important ways from induced closeness. Most notably, friendships extend across time and setting, whereas induced closeness exists only in the short duration of the RCIT (i.e. $9 \mathrm{~min}$ ) and in the laboratory. Friendships contain a past and a future; experimentally induced relationships do not. The notable durability and stability of friendships might actually facilitate the expression of the SSB. Perhaps friendship allows and enables both persons to be self-enhancing without fear of negative consequences for an already secure relationship. Friends may tolerate, even promote, each other's self-enhancement strivings with a resulting mutually beneficial psychological outcome (e.g. increased individual self-esteem). If so, the results of the present experiment will contradict those of Sedikides et al. (1998). On the other hand, friendships, like induced close relationships, may serve as a bound for self-enhancement, thus replicating Sedikides et al. (1998). Individuals, after all, have more positive views of friends than of strangers (Brown, 1986), and this may make individuals more likely to report favourable attributions for a friend's performance relative to own performance. Additionally, individuals may refrain from expressing self-enhancement strivings that reflect negatively on the friend, because they include the friend in their self-concept. 


\section{Overview}

Participants in this experiment were either same-sex friends or strangers. A modified version of Sedikides et al.'s (1998) methodology was used. Friends or strangers reported to the laboratory in pairs, completed a creativity test in adjoining rooms, were given randomly determined success or failure feedback, and attributed the test outcome to the self or the partner.

The SSB paradigm allowed the authors to pit the relationship-as-enabler and the relationship-as-bound hypotheses against each other. It was predicted that, consistent with past research, strangers will display the SSB. In the case of friendship, however, the authors engaged in conditional rather than straightforward predictions. If naturally occurring friendship initiates psychological processes similar to those of an artificially induced relationship, then dyad members should inhibit the SSB, thus replicating Sedikides et al. (1998) and lending support to the relationshipas-bound hypothesis. More specifically, the authors would observe an interaction involving relationship type and feedback type. On the other hand, if naturally occurring friendship activates psychological processes that are fundamentally different from those activated by laboratory-induced relationships, then dyad members should manifest the SSB, thus contradicting the Sedikides et al. (1998) findings and lending support to the relationship-as-enabler hypothesis. More specifically, the authors would observe only a main eff ect of feedback type.

\section{Method}

\section{Design}

A 2 (relationship type: friends, strangers) $\times 2$ (feedback type: success, failure) $\times 2$ (participant gender: female, male) balanced, between-participants design was used. The primary dependent variable was attribution of responsibility for the task outcome.

\section{Participants}

Participants were 128 students at the University of North Carolina at Chapel Hill, USA. (Six additional dyads were excluded, because at least one dyad member guessed correctly the fabricated nature of the feedback.) Participation in the experiment served as partial fulfilment of a course option in Introductory Psychology. One half of the participants responded to posted announcements that invited them to sign up for the experiment and report to the laboratory with a same-sex friend (friend condition); the other half responded to posted announcements that asked them to sign up on a list with other same-sex individuals, but not a friend (stranger condition). Relationship type was verified by the experimenter before the commencement of the experiment.

\section{Procedure and materials}

Upon arrival at the laboratory, an experimenter paired each participant with either their friend or a stranger. Immediately afterwards, the experimenter placed the participants alone in separate rooms where they remained for the rest of the experiment.

Relationship closeness manipulation check. The authors wanted to ascertain that the participants who reported with friends were relationally closer to each other than the participants who reported with 
strangers. They therefore asked participants to complete four single-item 9-point scales that measured participants' degree of (a) closeness, (b) similarity, (c) liking, and (d) likelihood of future friendship with the partner.

Interdependent-outcomes task. The participants were presented with what was purported to be a test of brainstorming in dyads, the 'Lange-Elliot Creativity Test'. Instructions to each participant included the following. First, each dyad member was asked to generate as many uses for specified objects as possible within a given time period. Secondly, the total number of unique uses generated by the dyad would be summed to create a combined score for the dyad. Thirdly, this combined score would be compared to scores obtained by a large normative sample.

Before beginning the test, participants reported the degree to which creativity was important to them on a 10-point scale with endpoints at (1) not at all important and (10) very important. Next, participants began the test by listing as many uses for a brick as possible. After $5 \mathrm{~min}$, the experimenter entered each room carrying a box, emptied each participant's responses into this same box, and asked participants to repeat the procedure by generating uses for a candle.

Following task completion, each participant received performance feedback. The type of feedback (i.e. success or failure) was determined randomly and reflected the dyad's combined performance. Participants were shown a feedback page. On the top of the page was a bell-shaped histogram. Each participant in the success feedback condition was shown a mark at the 93rd percentile; each participant in the failure feedback condition was shown a mark at the 31 st percentile. This written feedback was also accompanied by a verbal statement that the dyad did 'well' or 'poorly'.

Dependent measures. Participants received the dependent measures in the form of a booklet with one question per page. The rationale presented for the questions was that the combined scores used in the creativity test made it impossible for the experimenter to determine individual-level contributions. Participants were also assured of the confidentiality of their responses. That is, participants were told that their partner would be unaware of their responses in the booklet.

The SSB was measured with the following two questions: 'Who was most responsible for the outcome of this test?' and 'Who made the greatest POSITIVE contribution to this test?' Participants responded to both questions on scales with endpoints at (1) the other participant and (10) myself.

Subsequently the strength of feedback type manipulation was examined with the question: 'How well do you think that both you and the other participant did on this test?' Participants responded to both questions on a scale with endpoints at (1) not at all well and (10) very well. Finally, participants were debriefed carefully, thanked for their participation, and excused.

\section{Results}

\section{Manipulation checks}

Relationship closeness. The authors wanted to know whether friends and strangers differed in their reported level of closeness. First, a composite index was formed by averaging the four relationship closeness scales (i.e. closeness, similarity, liking, and future friendship; Cronbach's alpha $=.92)$. Next, this composite index was entered into a single-factor Analysis of Variance (ANOVA). As expected, friends ( $M=7.24)$ reported greater overall closeness to their partners than did strangers $(M=3.35$; $F(1,126)=343, p<.0001)$.

Creativity importance. Participants considered creativity to be important, as a $t$ test comparing the overall mean $(M=8.00)$ against the scale midpoint $(5.50)$ indicated $(t(127)=12.64, p<.0001)$. Furthermore, friends $(M=7.95)$ and strangers $(M=$ $8.05)$ did not differ in the importance they assigned to creativity $(F(1,126)=0.10$, $p<.75)$. 
Table 1. Attributions made by friends and strangers following success and failure feedback

Feedback type

Relationship type

Success Failure

$\begin{array}{lll}\text { Friends } & & \\ \quad M & 5.77 & 5.61 \\ \text { SD } & 1.32 & 1.20 \\ \text { Strangers } & & \\ \quad M & 6.25 & 4.99 \\ \text { SD } & 1.59 & 1.44\end{array}$

Note. High scores reflect greater attributed responsibility to the self.

Success and failure feedback. Participants in the success feedback condition $(M=8.48)$, relative to participants in the failure condition $(M=4.08)$, indicated that their dyads performed better on the creativity test $(F(1,120)=211, p<.0001)$. This finding confirms the eff ectiveness of the feedback type manipulation.

\section{Responsibility attributions}

The SSB measure consisted of two conceptually identical items : a responsibility item and a positive contribution item. In order to combine the two attribution items, first the positive contribution score reported by participants in the failure condition was reversed. ${ }^{2}$ This transformed positive outcome item and the responsibility item (as expected, the two items correlated significantly $(r(126)=.46, p<.0005))$ were then averaged to form a combined measure of outcome responsibility. On this measure, a significant Relationship Type $\times$ Feedback Type interaction indicates an influence of relationship type on the SSB.

Indeed, this interaction was significant $(F(1,120)=4.79, p<.03$ - see Table 1$){ }^{3}$ The authors proceeded with the relevant planned contrasts. Their predictions

${ }^{2}$ An explanation is needed for why the positive contribution scores were reversed. The responsibility and positive contribution items could not simply be averaged into one attribution measure because of each item's distinct phrasing (see Method section). This is most clearly communicated by outlining predictions for each item. If, consistent with the relationship-as-bound hypothesis, friendship bounds the SSB, an interaction between relationship type and feedback type on the responsibility item should be observed. In the stranger condition, individuals will take responsibility for success and deny responsibility for failure. In the friend condition, individuals will share responsibility for both successes and failures. On the positive contribution item, however, a main effect of relationship type should, simply, be observed. Strangers should report making a greater positive contribution to the task outcome than friends across levels of feedback type. Put another way, the non-reversed positive contribution item is limited in that it allows examination of the relative difference in the SSB between friends and strangers, but not the absolute degree of the SSB displayed by either friends or strangers. Reversing the item corrects for this limitation.

${ }^{3}$ There is a possibility that, because the analysis includes dyads, there is a problem of non-independence (Myers, DiCeceo, \& Lorch, 1981). That is, the responsibility scores of the members of each dyad may not be independent. In order to remove concerns about non-independence, the data were re-analysed using the average responsibility scores for each dyad as the dependent variable. The crucial Relationship Type $\times$ Feedback Type interaction remained significant $(F(1,56)=5.58, p<.022)$. 
pertaining to strangers were confirmed: strangers assumed greater personal responsibility for the success of the dyad than its failure $(t(62)=3.32, p<.002)$, thus exhibiting the SSB. Friends, however, did not assume different levels of personal responsibility for the dyad's success and failure $(t(62)=.52, p<.60)$. Consistently with the relationship-as-bound hypothesis, friends refrained from the SSB.

A feedback type main effect was also obtained $(F(1,120)=8.10, p<.0005)$. Overall, participants manifested the SSB: participants whose dyad succeeded $(M=$ $6.01)$ assumed greater personal responsibility for the test outcome than participants whose dyad failed $(M=5.30)$. The Feedback Type $\times$ Participant Gender interaction was not significant $(F(1,120)=0.05, p<.83)$. There was no difference between women and men in the degree to which they displayed the SSB. The Feedback Type $\times$ Relationship Type $\times$ Participant Gender interaction was not significant either $(F(1,120)=0.14, p<.71)$. Relationship type did not aff ect the manifestation of the SSB differentially in women and men.

\section{Discussion}

Summary of findings

Will friendship facilitate self-enhancement (relationship-as-enabler hypothesis), or will it inhibit self-enhancement (relationship-as-bound hypothesis)? This investigation examined the SSB in dyads who completed an interdependent-outcomes task. The findings were consistent with the relationship-as-bound hypothesis: friends (in contrast to strangers) refrained from the SSB.

The finding that strangers in interdependent-outcomes tasks manifest the SSB is in line with past research (Johnston, 1967; Sedikides et al., 1998; Wolosin et al., 1973). Additionally, the finding that friends refrain from the SSB is in line with the findings of Sedikides et al. (1998). Sedikides and colleagues, however, relied on induced close relationships, whereas the present research uses actual friendships.

One caveat is important to address at this time. Participants in the present study signed up either with a friend (friend condition) or without a friend (stranger condition). This may have influenced the results because individuals who signed up with a friend may have been more gregarious and perhaps less self-serving. Three additional factors, however, would argue against this hypothesis. First, the sign-up sheets were posted on a board with at least 40 (and up to 100) other sign-up sheets: Participants were not forced to choose between the two conditions used in the study. Secondly, participants in the stranger condition were simply asked to be sure not to sign up at the same time slot as a friend. This is not difficult at UNC because of the large $(500+)$ size of the participant pool. Finally, as noted in the preceding paragraph, the findings parallel nicely with those obtained by Sedikides et al. (1998) using induced close relationships.

\section{Implications}

The present findings carry several implications. The primary implication is the demonstration that relational context, specifically friendship, plays a critical part in 
suppressing self-enhancement. Why do friends refrain from the SSB in interdependent-outcomes tasks? This question is not addressed empirically in the present research, but several possible answers are offered and evaluated.

First, the nature of the social situation examined (i.e. a cooperative task) may have played a key role in reducing friends' self-enhancement strivings. Perhaps the selfserving attributions exhibited by friends would have been equal to or greater than those manifested by strangers if the context was competitive. ${ }^{4}$ This issue deserves future research attention.

Secondly, friends are concerned with maintaining their relational bond. Thus, friends may refrain from the SSB because they perceive it as a slight directed to the partner that may damage the relationship. The results of the present experiment, however, argue against such an interpretation because the responsibility attributions were made under private and confidential circumstances. Nevertheless, it is possible that participants would be concerned about the attributions being revealed in discussions with the friend subsequent to the experimental task.

Also, friends may refrain from the SSB because, contrary to strangers, they expect that their partner will refrain from the SSB. Such expectancies, which reflect underlying friendship norms (Argyle \& Henderson, 1984), have indeed been found to be present in close dyads (when closeness was induced experimentally) preparing to engage in interdependent-outcomes tasks (Sedikides, Campbell, Reeder, \& Elliot, 1999b).

Additionally, friends may experience a unique connection with each other. This connection may include incorporation processes proposed by self-expansion theory (Aron \& Aron, 1997), identification processes proposed by the self-evaluation maintenance model (Tesser, 1988), or categorization processes proposed by selfcategorization theory (Turner et al., 1994). Indeed, friends, in contrast to strangers, may experience a degree of overlap in their self-concepts such that they consider the success of the other dyad member as an own success. This would make giving credit to the partner as enhancing as giving credit to the self.

Finally, individuals may have more positive impressions of a dyad partner who is a friend than a dyad partner who is a stranger. Arguably, a more positive impression of the partner, particularly in the domain of creativity, will decrease self-serving responsibility attributions. For example, if Jeff collaborates on a successful project with a partner whom he considers creative, Jeff will be less likely to make self-serving attributions than if he considers the collaborator uncreative. This positive impression explanation has received empirical support with artificially induced relational closeness: Sedikides et al. (1998) found that the display of the SSB was mediated by partner impressions.

\section{Concluding remarks}

In conclusion, this research indicates that friendship places boundaries on individual self-enhancement. This phenomenon is most likely the result of norms or expectancies associated with friendship, inclusion of close others in the self-concept, or the

\footnotetext{
${ }^{4}$ The authors thank a reviewer for this suggestion.
} 
positive regard in which friends are held. It is hoped that the results of the present study propel future research on how friendship (and close relationships, more generally) influence an individual's self-enhancement strivings.

\section{Acknowledgements}

The authors thank Carrie Beck, Robbie Brafford, Cameron Calowell and Martin Curtis for their assistance in conducting this experiment.

\section{References}

Argyle, M., \& Henderson, M. (1984). The rules of friendship. Journal of Social and Personal Relationships, $1,211-237$.

Aron, A., \& Aron, E. N. (1997). Self-expansion motivation and including other in the self. In S. Duck (Ed.), Handbook of personal relationships: Theory, research, and intervention (2nd ed., pp. 251-270). Chichester: Wiley.

Beach, S. R. H., \& Tesser, A. (1995). Self-esteem and the extended self-evaluation maintenance model: The self in social context. In M. Kernis (Ed.), Effracy, agency, and self-esteem (pp. 145-170). New York: Plenum.

Blumberg, H. H. (1972). Communication of interpersonal evaluations. Journal of Personality and Social Psychology, 23, 157-162.

Brown, J. D. (1986). Evaluations of self and others: Self-enhancement biases in social judgments. Social Cognition, 4, 353-376.

Brown, J. D., \& Dutton, K. A. (1995). Truth and consequences: The costs and benefits of accurate self-knowledge. Personality and Social Psychology Bulletin, 21, 1288-1296.

Campbell, W. K., \& Sedikides, C. (1999). Self-threat magnifies the self-serving bias: A meta-analytic integration. Review of General Psychology, 3, 23-43.

Clark, M. S. (1984). Record keeping in two types of relationships. Journal of Personality and Social Psychology, 47, 549-557.

Cohen, S., \& Hoberman, H. (1983). Positive events and social supports as buffers of life change stress. Journal of Applied Social Psychology, 13, 99-125.

Cohen, S., \& Wills, T. A. (1985). Stress, social support, and the buffering hypothesis. Psychological Bulletin, 98, 310-357.

Felson, R. B. (1993). The (somewhat) social self: How others affect self-appraisals. In J. Suls (Ed.), Psychological perspectives on the self (Vol. 4, pp. 1-26). Hillsdale, NJ : Erlbaum.

Goffman, E. (1959). The presentation of self in everyday life. New York: Doubleday.

Heider, F. (1958). The psychology of interpersonal relations. New York: Wiley.

James, W. (1890). The principles of psychology (Vol. 1). New York: Henry Holt \& Co.

Johnston, W. A. (1967). Individual performance and self-evaluation in a simulated team. Organizational Behavior and Human Performance, 2, 309-328.

Jones, S. C. (1973). Self and interpersonal evaluations: Esteem theories vs. consistency theories. Psychological Bulletin, 79, 185-199.

Major, B., Testa, M., \& Bylsma, W. H. (1991). Response to upward and downward comparisons: The impact of esteem relevance and perceived control. In J. Suls \& T. A. Wills (Eds.), Social comparison: Contemporary theory and research (pp. 237-260). Hillsdale, NJ : Erlbaum.

Manis, M., Cornell, S. D., \& Moore, J. C. (1974). The transmission of attitude-relevant information through a communication chain. Journal of Personality and Social Psychology, 30, 81-94.

Myers, J. L., DiCecco, J. V., \& Lorch, R. F. Jr (1981). Group dynamics and individual performances: Pseudogroup and quasi-F analyses. Journal of Personality and Social Psychology, 40, 86-98.

Rhodewalt, F. T., Morf, C., Hazlett, S., \& Fairchild, M. (1991). Self-handicapping: The role of discounting and augmentation in the preservation of self-esteem. Journal of Personality and Social Psychology, 61, 122-131. 
Rusbult, C. E., \& Arriaga, X. B. (1997). Interdependence theory. In S. Duck (Ed.), Handbook of personal relationships: Theory, research and intervention (2nd ed., pp. 221-250). Chichester: Wiley.

Sedikides, C. (1993). Assessment, enhancement, and verification determinants of the self-evaluation process. Journal of Personality and Social Psychology, 65, 317-338.

Sedikides, C., Campbell, W. K., Reeder, G. D., \& Elliot, A. J. (1998). The self-serving bias in relational context. Journal of Personality and Social Psychology, 74, 378-386.

Sedikides, C., Campbell, W. K., Reeder, G. D., \& Elliot, A. J. (1999a). The Relationship Closeness Induction Task. Representative Research in Social Psychology, 23, 1-4.

Sedikides, C., Campbell, W. K., Reeder, G. D., \& Elliot, A. J. (1999b). How close relationships bound selfenhancement: The role of expectancies and attributional reciprocity. Unpublished manuscript, University of North Carolina at Chapel Hill.

Sedikides, C., \& Strube, M. J. (1997). Self-evaluation: To thine own self be good, to thine own self be sure, to thine own self be true, and to thine own self be better. In M. P. Zanna (Ed.), Advances in experimental social psychology (Vol. 29, pp. 209-269). New York: Academic Press.

Smith, E. R., \& Henry, S. (1996). An in-group becomes part of the self: Response time evidence. Personality and Social Psychology Bulletin, 22, 635-642.

Taylor, S. E., \& Koivumaki, J. H. (1976). The perception of self and others: Self-enhancement biases in social judgments. Journal of Personality and Social Psychology, 33, 403-408.

Tesser, A. (1988). Toward a self-evaluation model of social behavior. In L. Berkowitz (Ed.), Advances in experimental social psychology (Vol. 21, pp. 181-227). San Diego: Academic.

Tesser, A., \& Rosen, S. (1975). The reluctance to transmit bad news. In L. Berkowitz (Ed.), Advances in experimental social psychology (Vol. 8, pp. 193-232). New York: Academic Press.

Tice, D. M. (1991). Esteem protection or enhancement? Self-handicapping motives and attributions differ by trait self-esteem. Journal of Personality and Social Psychology, 69, 711-725.

Turner, J. C., Oakes, P. J., Haslam, A., \& McGarty, C. (1994). Self and collective: Cognition and social context. Personality and Social Psychology Bulletin, 20, 454-463.

Weary-Bradley, G. (1978). Self-serving biases in the attribution process: A reexamination of the fact or fiction question. Journal of Personality and Social Psychology, 36, 56-71.

Wolosin, R. J., Sherman, S. J., \& Till, A. (1973). Effects of cooperation and competition on responsibility attribution after success and failure. Journal of Experimental Social Psychology, 9, 220-235.

Zuckerman, M. (1979). Attribution of success and failure revisited, or: The motivational bias is alive and well in attribution theory. Journal of Personality, 47, 245-287. 